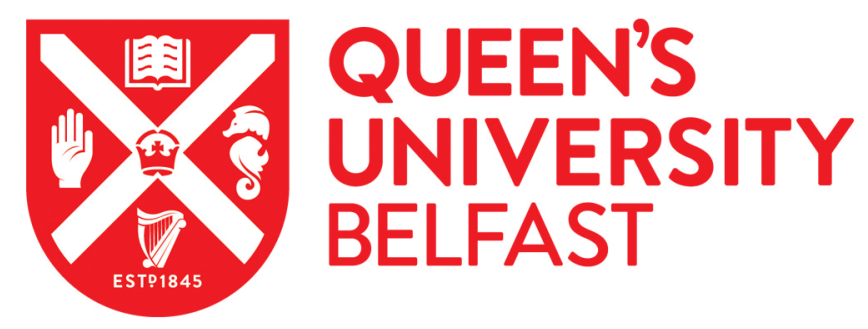

\title{
Reply (Correspondence) to Safety of Spectacles for Children's Vision: A Cluster-Randomized Controlled Trial
}

Ma, X., Congdon, N., Yi, H., Pang, X., Zhou, Z., Meltzer, M. E., He, M., Liu, Y., Shi, Y., \& Rozelle, S. (2016).

Reply (Correspondence) to Safety of Spectacles for Children's Vision: A Cluster-Randomized Controlled Trial. American Journal of Ophthalmology, 163, 196-197. https://doi.org/10.1016/j.ajo.2015.12.022

Published in:

American Journal of Ophthalmology

Document Version:

Peer reviewed version

Queen's University Belfast - Research Portal:

Link to publication record in Queen's University Belfast Research Portal

Publisher rights

(c) 2016 Elsevier Ltd. This manuscript version is made available under the CC-BY-NC-ND 4.0 license http://creativecommons.org/licenses/by$\mathrm{nc}-\mathrm{nd} / 4.0 /$, which permits distribution and reproduction for non-commercial purposes, provided the author and source are cited

\section{General rights}

Copyright for the publications made accessible via the Queen's University Belfast Research Portal is retained by the author(s) and / or other copyright owners and it is a condition of accessing these publications that users recognise and abide by the legal requirements associated with these rights.

Take down policy

The Research Portal is Queen's institutional repository that provides access to Queen's research output. Every effort has been made to ensure that content in the Research Portal does not infringe any person's rights, or applicable UK laws. If you discover content in the Research Portal that you believe breaches copyright or violates any law, please contact openaccess@qub.ac.uk. 
Safety of Spectacles for Children's Vision: A Cluster-Randomized Controlled Trial

Xiaochen Ma*1,9, Nathan Congdon*2, 3, 4, Hongmei $\mathrm{Yi}^{5}$, Zhongqiang Zhou ${ }^{2}$, Xiaopeng Pang ${ }^{6}$, Mirjam E. Meltzer ${ }^{2}$, Yaojiang Shi ${ }^{7}$, Mingguang $\mathrm{He}^{2}$, Liu Yizhi, ${ }^{2}$ Scott Rozelle ${ }^{8}$

${ }^{1}$ China Center for Health Development Studies, Peking University, Beijing, China;

${ }^{2}$ State Key Laboratory of Ophthalmology and Division of Preventive Ophthalmology;

Zhongshan Ophthalmic Center, Sun Yat-sen University, Guangzhou, China;

${ }^{3}$ ORBIS International, New York, USA;

${ }^{4}$ Center for Public Health and TREE Center, Queen's University Belfast, Belfast, United

Kingdom;

${ }^{5}$ Center for Chinese Agricultural Policy, Institute of Geographical Sciences and Natural

Resources Research, Chinese Academy of Sciences, Beijing China;

${ }^{6}$ School of Agricultural Economics and Rural Development, Renmin University of China,

Beijing, China;

${ }^{7}$ Center for Experimental Economics for Education, Shaanxi Normal University, Xi'an, China;

${ }^{8}$ Freeman Spogli Institute of International Studies, Stanford University, Stanford, USA;

${ }^{9}$ Stanford Center For International Development, Stanford University, Stanford, USA

Inquiries to Prof Nathan Congdon, TREE Centre, Centre for Public Health, Queen's University Belfast, Royal Victoria Hospital, Institute for Clinical Sciences Block N, Belfast UK BT12 6AB; OR State Key Laboratory of Ophthalmology, Zhongshan Ophthalmic Center, Sun Yat-Sen University, Guangzhou, PRC 510060; e-mail: ncongdon1@gmail.com 
Dear Editor:

We appreciate the interest of Drs Galvis et al in our work. ${ }^{1}$ It has been suggested that under-correction of children's refractive error might retard myopia progression. Previous studies, ${ }^{2,3}$ limited by size, have generally not been consistent with this. We performed a post hoc analysis on data from our large trial of spectacle provision in China, and found no evidence of worsening visual acuity (VA) among children randomized to receive glasses compared to Controls. In fact, the final uncorrected VA of Treatment Group children was significantly better than Controls.

Galvis et al offer several points about these results:

- The finding is potentially not meaningful because it relates to VA rather than refractive power: Policy-makers in healthcare and education are more concerned with preservation of VA than refractive changes, and we feel our chosen outcome is most meaningful for our intended audience. We agree that other factors, such as effort and lighting, can affect measured VA, but the randomized design in such large trials tends to reduce such differences between groups. Additionally, examiners were masked to group assignment, and our analyses utilized uncorrected VA, making it unlikely that glasses wear would have affected VA measurement.

- The magnitude of the observed visual acuity difference was small: The difference in visual acuity between groups was roughly a quarter of a line, which was statistically significant, but not likely of clinical importance. The critical fact is that we found no evidence of VA being worse among Treatment Group children. We have already established that providing glasses to children brings significant educational benefits. ${ }^{4} \mathrm{~A}$ major impediment to programs of spectacle distribution in China has been the concern that children's vision might be harmed by glasses. This study was powered to detect even relatively small degrees of vision worsening, and the fact that no such worsening was found is strong evidence that providing spectacles to children in this setting is safe.

- The period of follow-up was short: The period of follow-up was roughly one school year. In studies of this magnitude, involving hundreds of schools, tracking movement of children between schools over more than a single school year is impractical. In any event, we demonstrated that the study was adequately-powered to detect small changes in VA that would occur over this time span. 
- More research is needed: As professional researchers, we are happy to agree that our work is still needed. However, the pertinent question is whether we have sufficient evidence that spectacles may safely be given to children without fear of harming their uncorrected vision, making them "dependent" on glasses. Compared to having no glasses, the reality at baseline for $85 \%$ of myopic children in this and similar ${ }^{5}$ studies in China, we feel these results clearly demonstrate giving glasses is safe for children. Trials of this size are expensive, and we do not feel that more evidence of spectacle safety is needed in this setting before undertaking badly-needed programs of distribution.

Best regards 


\section{References}

1. Ma X, Congdon N, Yi H, et al. Safety of Spectacles for Children's Vision: A Cluster-Randomized Controlled Trial. Am J Ophthalmol 2015;160(5):897-904.

2. Chuang K, Mohidin N, O'Leary DJ. Undercorrection of myopia enhances rather than inhibits myopia progression. Vision Res 2002;42(22):2555-9.

3. Adler $\mathrm{D}$, Millodot $\mathrm{M}$. The possible effect of undercorrection on myopic progression in children. Clin Exp Optom 2006;89(5):315-21.

4. Ma X, Zhou Z, Yi H, et al. Effect of providing free glasses on children's educational outcomes in China: cluster randomized controlled trial. BMJ 2014;349:g5740.

5. Wang X, Yi H, Lu L, et al. Population Prevalence of Need for Spectacles and Spectacle Ownership Among Urban Migrant Children in Eastern China. JAMA Ophthalmol 2015;133(12):1399-1406. 